\title{
GENDER DIFFERENCES IN THE RETIREMENT BEHAVIOUR OF THE ELDERLY USING NON-LINEAR DECOMPOSITION METHODS
}

\author{
DOI: 10.17261/Pressacademia.2019.1115 \\ JEFA- V.6-ISS.3-2019(6)-p.170-183
}

Makbule Gulbin Erdem

Pamukkale University, Department of Labour Economics and Industrial Relations, Kinikli Kampus, Denizli, Turkey. mgulbine@pau.edu.tr ,ORCID: 0000-0002-7731-3991

Date Received: August 1, 2019

Date Accepted: September 16, 2019

To cite this document

Erdem, M. G. (2019). Gender differences in the retirement behaviour of the elderly using non-linear decomposition methods. Journal of Economics, Finance and Accounting (JEFA), V.6(3), p.170-183.

Permanent link to this document: http://doi.org/10.17261/Pressacademia.2019.1115

Copyright: Published by PressAcademia and limited licenced re-use rights only.

\section{ABSTRACT}

Purpose- This paper examines factors of the gender disparity among British people on their retirement decisions using nonlinear decomposition methods and which factors cause gender differentials in retirement decisions between 1991 and 2013 . In this respect, both the British Household Panel Survey and Understanding Society are utilised.

Methodology- Both Fairlie (1999) and Yun (2004) methods are used to examine the impacts of observed demographic and income factors on gender differentials of retirement decisions.

Findings- Age, hourly earnings, non-labour income and pension eligibility increase the gender gap, whereas education, good health conditions and being a homeowner act to reduce the gender gap.

Conclusion- Even though the labour force participation of older women has consistently been increasing over the past two decades, the gender disparity influenced by demographic and financial factors has not been significantly reduced over time. The demographic and financial factors mostly explained the gender gap; however, their effects significantly change due to the explained and unexplained parts during the 20-year period.

Keywords: Oaxaca decomposition, nonlinear models, binary choice, retirement, UK.

JEL Codes: J14, J16, J26

\section{INTRODUCTION}

The labour force attachment of older women has increased at a fast rate over the past 20 years, functioning as a decisive push factor that has affected the employment rates of older people since the mid-1990s in the United Kingdom (UK). DWP (2015) highlights that the employment gap between men aged 50-64 and women of the same age declined from approximately $28 \%$ three decades ago to almost $11 \%$ in 2015. Using methods to decompose the gender gap in retirement decisions, this study investigates to what extent differences between the British women and men can be explained by differences in characteristics such as health, education and income level, and by differences in behavioural responses associated with those coefficients. In this study, both the British Household Panel Survey (BHPS) and the Understanding Society (UKHLS) ${ }^{1}$ are utilised. In this context, the research questions focus on the main factors that causing gender differences in retirement behaviours, how these differences change over time, and how variations between genders can be explained by disparities in observable characteristics.

The prevalent decomposition model proposed by Oaxaca (1973) and Blinder (1973) is used to decompose the labour force decision by measuring the mean differentials between males and females from the differences in observable and unobservable characteristics. Under some conditions, these unexplained differentials can be attributed to the discriminatory behaviour of male-female groups. Therefore, the Oaxaca-Blinder decomposition model has often been applied to analyse the impact of discrimination in the literature. The original Oaxaca-Blinder decomposition can be applied to linear models. However, some extensions of Oaxaca and Blinder decomposition can be applied to non-linear models as well. Both Fairlie

\footnotetext{
${ }^{1}$ It is also known as the UK Household Longitudinal Survey.
} 
(1999) and Yun (2004) methods are used to examine the impacts of observed demographic and income factors on gender differentials of retirement decisions. The reason for using multiple decomposition models is that each may have some drawbacks. Thus, the findings obtained from both methodologies allow us to compare the results of the detailed decomposition techniques to determine which factors have the highest impact on the gender gap. Moreover, it allows us to observe changes in their effects over a 22-year period by taking the first wave of the BHPS covering the period of 1991-1992, the last wave of the BHPS indicating 2008-2009 period covering the global financial crisis and the 2012-2013 period obtained from the UKHLS sample called as the post-crisis period.

The rest of this study is organised as follows: Section 2 summarises a background for studies using nonlinear decomposition methodology. Section 3 describes the non-linear decomposition methods in detail. The data and descriptive statistics are presented in the same section, and in Section 4, the estimation results are discussed. The last section provides the concluding remarks.

\section{LITERATURE REVIEW}

The literature can be divided into two groups: studies using linear methods (such as Gangl and Ziefle, 2009; Chiu and Chen, 2013; Gunalp et al., 2015) and studies using nonlinear decomposition methods (Fairlie, 1999; Yun, 2000, 2004; Kalb et al., 2012; Bazen et al., 2016)².

Among using nonlinear decomposition methodologies, Fairlie (1999) developed a decomposition method for binary choice models as an extension of the Oaxaca-Blinder decomposition model. Another application of nonlinear Oaxaca-Blinder decomposition based on first-order Taylor series expansion for modelling binary outcomes in probit model was proposed by Yun (2004) to analyse racial differences in labour market participation rates. According to Yun's results, the racial gap in women's participation rates is explained exclusively by the effects of differences in coefficients, especially age variables. Powers and Pullum (2006) added some extensions to the models developed by Nielson (1998) and Yun (2004) to reduce path dependency problems.

Labour market attachment in Australia was addressed by Kalb et al. (2012) using a nonlinear version of the Blinder-Oaxaca decomposition method by Bauer and Sinning (2008) and the method proposed by Powers, Yoshioka and Yun (2011) for detailed decomposition. They showed that at least two-thirds of the racial gap in the labour market attachment for women can be attributed to differences in the unobserved characteristics between the two populations, whereas 42.5 percent of the racial gap in labour force participation for men can be explained by differences in explanatory factors. Bazen et al. (2016) applied nonlinear decomposition methods based on mean value theorem to analyse the gender gap in earnings for France. The differences in observable factors are more important component in explaining the gender differential in earnings and the key factor derived from the detailed decomposition is the differences in education.

\section{DATA AND METHODOLOGY}

\subsection{Methodology}

In general, the Oaxaca-Blinder decomposition model aims to explain the distribution of the outcome variable by a set of factors that vary systematically with the socioeconomic status. The differences gathered from two groups can be decomposed into two parts. The first one contains both the part that is explained by observable characteristics (explained differentials or endowment effects), such as education, health or income, and the residual part that cannot be accounted for by such differences in determinants of retirement decisions (unexplained differentials or returns to risk). As emphasised by Jann (2008), this technique is easy to implement in linear regression models as it requires coefficient estimates from the linear regression for the outcome of interest and sample means of the independent variables in the regression. However, if the outcome is binary, it becomes more complicated since the coefficient estimates obtained from binary models cannot be used directly in the standard Oaxaca-Blinder decomposition equation. This leads inconsistent parameter estimates and misleading decomposition results.

For binary models, the differences in the probabilities between females and males can be decomposed by the effects of the differences in endowment effects and the effects of the differences in the coefficients. Formally, the decomposition of the differences in probabilities between females and males can be described as follows:

$$
\overline{Y_{M}}-\overline{Y_{F}}=\hat{\Delta}=\left(\overline{\Phi\left(X_{l M} \widehat{\beta_{\ell M}}\right)}-\overline{\Phi\left(X_{l F} \widehat{\beta_{M}}\right)}\right)+\left(\overline{\Phi\left(X_{l F} \widehat{\beta_{M}}\right)}-\overline{\Phi\left(X_{l F} \widehat{\beta_{F}}\right)}\right)
$$

\footnotetext{
2 Extensions of Oaxaca-Blinder methodology can be used in various models. See Fairlie, 1999, 2005; Yun 2000, 2004; Powers and Pullum, 2006; Prichette and Yun, 2009; Bowblis and Yun, 2010 for logit and probit models, Wagstaff and Nguyen, 2001; Powers and Yun, 2009; Bazen et al., 2016 for hazard rate models.
} 
where $Y_{\ell}$ is the average of the computed probability of being retired, while $\widehat{\beta_{\ell}}$ is a $K x 1$ vector of probit coefficients and $X_{i \ell}$ acts as a vector of both individual and household characteristics as the average of the computed probability using a standard normal cumulative distribution (CDF), $\Phi$. The decomposition equation used for probit models is divided into two parts: the first one captures differences in standard normal CDFs, which represent the effects of different individual characteristics between two groups (differences in observable characteristics), whereas the second one captures differences in standard normal CDFs, which represent the effects of different probit coefficients between two groups (differences in unobservable factors). Such measures are required as there is no unique way to find the effects of differences in each character and the effects of differences in each coefficient separately from the equation (1) owing to nonlinearity. Yun (2004) proposed a simple modification of equation (1) formed of a two-step approximation to obtain the effects of differences in each character and the effects of differences in each coefficient. In the first step, the sample average of the standard normal CDF is approximated by the standard normal CDF at the sample average of individual characteristics.

In the second step, the first-order Taylor approximation is used to linearize the characteristics and coefficient effects around $\bar{X}_{i F} \beta_{F}$ and $\bar{X}_{i M} \beta_{M}$, respectively. The final decomposition after the Taylor expansion are:

$$
\overline{Y_{M}}-\overline{Y_{F}}=\left(\bar{X}_{i M}-\bar{X}_{i F}\right) \widehat{\beta_{M}} \phi\left(\bar{X}_{i M} \widehat{\beta_{M}}\right)+\bar{X}_{i F}\left(\widehat{\beta_{M}}-\widehat{\beta_{F}}\right) \phi\left(\bar{X}_{i F} \widehat{\beta_{F}}\right)+\widehat{U}_{R}+\widehat{U}_{L}
$$

where $\phi\left(\bar{X}_{i \ell} \widehat{\beta_{\ell}}\right)=d\left(\Phi\left(\bar{X}_{i \ell} \widehat{\beta_{\ell}}\right) / d\left(\bar{X}_{i \ell} \widehat{\beta_{\ell}}\right)\right.$, i.e $\phi($.$) is the first-order derivative of the cumulative distribution function \Phi()$. for $\ell=F, M$ and,

$$
\widehat{U}_{L}=\left(\Phi\left(\bar{X}_{i M} \widehat{\beta_{M}}\right)-\Phi\left(\bar{X}_{i F} \widehat{\beta_{F}}\right)\right)-\left[\left(\bar{X}_{i M}-\bar{X}_{i F}\right) \widehat{\beta_{M}} \phi\left(\bar{X}_{i M} \widehat{\beta_{M}}\right)+\bar{X}_{i F}\left(\widehat{\beta_{M}}-\widehat{\beta_{F}}\right) \phi\left(\bar{X}_{i F} \widehat{\beta_{F}}\right)\right],
$$

$\widehat{U}_{R}, \widehat{U}_{L}$ and $\phi($.$) are all scalars. Both \widehat{U}_{i R}$ and $\widehat{U}_{i L}$ are approximation residuals derived from evaluation of the CDF at the mean values and by using the first Taylor expansion, respectively.

There are some challenges in the computation of detailed decompositions for non-linear models. Because of nonlinearity, the detailed decomposition of the two components into the contribution of each variable, even if the decomposition is linearised using marginal effects, would not add up to the total. Fairlie (2005) proposes an alternative methodology based on a series of counterfactuals, where the coefficient of each variable is switched to reference group values in the sequence. In this method, the decomposition estimates obtained depend on the randomly chosen subsample of females. Ideally, the results achieved gender using this decomposition model should approximate the results obtained by matching the entire female and male samples. A simple method of approximating this hypothetical decomposition is to draw a large number of random subsamples from females, randomly match each of these randomly drawn subsamples of females to the full male sample, and then calculate separate decomposition estimates. The mean value of estimates from distinct decompositions is computed and used to approximate the results for the entire female sample. However, the decomposition is sensitive to the order of the decomposition leading to path dependency ${ }^{3}$ (Fortin et al., 2011).

Following Fairlie (2005), non-linear version of the standard Blinder-Oaxaca decomposition for linear regression, $Y=$ $F\left(X_{i \ell} \hat{\beta}_{i \ell}\right)$ can be written as

$$
\bar{Y}_{M}-\bar{Y}_{F}=\left[\sum_{i=1}^{N_{M}} \frac{F\left(X_{i M} \widehat{\beta}_{M}\right)}{N_{M}}-\sum_{i=1}^{N_{F}} \frac{F\left(X_{i F} \widehat{\beta}_{M}\right)}{N_{F}}\right]+\left[\sum_{i=1}^{N_{F}} \frac{F\left(X_{i F} \widehat{\beta}_{M}\right)}{N_{F}}-\sum_{i=1}^{N_{F}} \frac{F\left(X_{i F} \widehat{\beta}_{F}\right)}{N_{F}}\right]
$$

where $N_{M}$ and $N_{F}$ are the sample sizes of both males and females. Fairlie (2005) used this above equation as $\bar{Y}_{\ell}$ does not necessarily equal $F\left(\bar{X}_{\ell} \hat{\beta}_{\ell}\right) .{ }^{4}$ The first bracket in the equation (3) shows the part of the gender gap that is due to the group differences in distributions of $X$, which show observable factors while the second term represents the other differences in the coefficients (Fairlie, 2005:307). The second part also captures the discrimination effect due to the group differences in unobserved endowments.

\subsection{Data and Summary Statistics}

Both the BHPS and the UKHLS dataset are longitudinal surveys of households containing rich socio-demographic information. The BHPS was originally designed as an indefinite life panel; however, it was terminated at the end of 2008. It consists of 18 waves with annual interviews from the first survey year of 1991 to the last survey year of 2008. In 1997, an additional sample

\footnotetext{
${ }^{3}$ Following Fairlie (2005), 1,000 random subsamples of females are used for deriving these means.

${ }^{4}$ Equation (3) is the generalized version of the Blinder-Oaxaca decomposition.
} 
was integrated with the BHPS for European Community Household Panel (ECHP) survey, and further 'booster' samples were added in 1999 for Scotland and Wales, and for Northern Ireland in 2001.

It is currently incorporated into the UKHLS, enriched by a new set of respondents with whom interviewing began in 2009. The UKHLS is an indefinite life household panel survey designed as an extension and more comprehensive form of the BHPS from 2009. It has a larger sample size than the BHPS, having an over-sample of ethnic minorities, a health and biomarkers component, and a larger geographical spread (Longhi and Nandi, 2015).

Table 1: Summary Statistics of the Sample by Gender: Female Group

\begin{tabular}{|c|c|c|c|c|c|c|}
\hline & \multicolumn{2}{|c|}{ 1991-1992 } & \multicolumn{2}{|c|}{ 2008-2009 } & \multicolumn{2}{|c|}{ 2012-2013 } \\
\hline & Mean & Std. Dev. & Mean & Std. Dev. & Mean & Std. Dev. \\
\hline Labour Force Status & 0.515 & 0.500 & 0.441 & 0.497 & 0.397 & 0.489 \\
\hline Age & 57.2 & 4.684 & 57.4 & 4.498 & 57.2 & 4.695 \\
\hline Poor & 0.106 & 0.308 & 0.120 & 0.325 & 0.095 & 0.294 \\
\hline Fair & 0.214 & 0.410 & 0.222 & 0.416 & 0.166 & 0.373 \\
\hline Good & 0.452 & 0.498 & 0.493 & 0.500 & 0.302 & 0.459 \\
\hline Excellent & 0.228 & 0.420 & 0.164 & 0.371 & 0.436 & 0.496 \\
\hline Spouse/Partner & 0.730 & 0.444 & 0.755 & 0.430 & 0.701 & 0.458 \\
\hline Owned House & 0.435 & 0.496 & 0.501 & 0.500 & 0.445 & 0.497 \\
\hline Mortgage & 0.305 & 0.461 & 0.326 & 0.469 & 0.334 & 0.472 \\
\hline Rented House & 0.260 & 0.439 & 0.174 & 0.379 & 0.221 & 0.415 \\
\hline Caring Responsibility & 0.071 & 0.256 & 0.090 & 0.287 & 0.085 & 0.279 \\
\hline Higher Degree+ & 0.031 & 0.173 & 0.140 & 0.347 & 0.359 & 0.480 \\
\hline HND/HNC or A Level & 0.098 & 0.298 & 0.210 & 0.407 & 0.145 & 0.352 \\
\hline O/CSE Level & 0.172 & 0.377 & 0.296 & 0.457 & 0.334 & 0.472 \\
\hline No Qualification & 0.699 & 0.459 & 0.354 & 0.479 & 0.162 & 0.369 \\
\hline In (Hourly Earnings) & 1.832 & 0.321 & 2.256 & 0.365 & 2.378 & 0.398 \\
\hline In (Non-Labour Inc.) & 4.120 & 2.230 & 4.456 & 2.578 & 4.235 & 2.966 \\
\hline In (Other HH Income) & 5.901 & 2.850 & 6.951 & 0.730 & 6.356 & 3.197 \\
\hline Having Child & 0.037 & 0.188 & 0.062 & 0.241 & 0.065 & 0.247 \\
\hline No of Pens. Age & 0.540 & 0.712 & 0.557 & 0.720 & 0.549 & 0.721 \\
\hline Pension & 0.203 & 0.402 & 0.244 & 0.430 & 0.220 & 0.414 \\
\hline North East & 0.052 & 0.222 & 0.031 & 0.173 & 0.043 & 0.204 \\
\hline North West & 0.127 & 0.334 & 0.085 & 0.279 & 0.104 & 0.305 \\
\hline Yorkshire \& Humber & 0.084 & 0.277 & 0.069 & 0.253 & 0.081 & 0.273 \\
\hline East Midlands & 0.074 & 0.262 & 0.054 & 0.226 & 0.079 & 0.269 \\
\hline West Midlands & 0.092 & 0.289 & 0.055 & 0.228 & 0.083 & 0.275 \\
\hline East of England & 0.082 & 0.275 & 0.068 & 0.251 & 0.091 & 0.287 \\
\hline London & 0.101 & 0.302 & 0.052 & 0.223 & 0.107 & 0.309 \\
\hline South East & 0.143 & 0.350 & 0.099 & 0.299 & 0.130 & 0.336 \\
\hline South West & 0.088 & 0.283 & 0.071 & 0.257 & 0.095 & 0.294 \\
\hline
\end{tabular}




\begin{tabular}{lcccccc}
\hline Wales & 0.064 & 0.244 & 0.204 & 0.403 & 0.083 & 0.275 \\
Scotland & 0.093 & 0.290 & 0.212 & 0.409 & 0.105 & 0.306 \\
\hline Number of Obs. & \multicolumn{2}{c}{1036} & \multicolumn{2}{c}{1440} & & 5733 \\
\hline \hline
\end{tabular}

Table 2: Summary Statistics of the Sample by Gender: Male Group

\begin{tabular}{|c|c|c|c|c|c|c|}
\hline & \multicolumn{2}{|c|}{ 1991-1992 } & \multicolumn{2}{|c|}{ 2008-2009 } & \multicolumn{2}{|c|}{ 2012-2013 } \\
\hline & Mean & Std. Dev. & Mean & Std. Dev. & Mean & Std. Dev. \\
\hline Labour Force Status & 0.262 & 0.440 & 0.242 & 0.429 & 0.278 & 0.448 \\
\hline Age & 57.2 & 4.669 & 57.2 & 4.568 & 57.3 & 4.733 \\
\hline Poor & 0.107 & 0.309 & 0.100 & 0.301 & 0.090 & 0.286 \\
\hline Fair & 0.184 & 0.388 & 0.232 & 0.422 & 0.156 & 0.363 \\
\hline Good & 0.417 & 0.493 & 0.466 & 0.499 & 0.320 & 0.467 \\
\hline Excellent & 0.292 & 0.455 & 0.201 & 0.401 & 0.434 & 0.496 \\
\hline Spouse/Partner & 0.841 & 0.365 & 0.830 & 0.376 & 0.772 & 0.419 \\
\hline Owned House & 0.365 & 0.482 & 0.450 & 0.498 & 0.402 & 0.490 \\
\hline Mortgage & 0.409 & 0.492 & 0.398 & 0.490 & 0.384 & 0.486 \\
\hline Rented House & 0.225 & 0.418 & 0.153 & 0.360 & 0.213 & 0.410 \\
\hline Caring Responsibility & 0.057 & 0.232 & 0.077 & 0.266 & 0.072 & 0.259 \\
\hline Higher Degree+ & 0.056 & 0.231 & 0.150 & 0.357 & 0.360 & 0.480 \\
\hline HND/HNC or A Level & 0.154 & 0.361 & 0.318 & 0.466 & 0.210 & 0.407 \\
\hline O/CSE Level & 0.176 & 0.381 & 0.234 & 0.424 & 0.307 & 0.461 \\
\hline No Qualification & 0.614 & 0.487 & 0.298 & 0.457 & 0.123 & 0.329 \\
\hline In (Hourly Earnings) & 2.196 & 0.356 & 2.506 & 0.389 & 2.611 & 0.436 \\
\hline In (Non-Labour Inc.) & 4.269 & 2.381 & 3.889 & 2.908 & 4.091 & 3.125 \\
\hline In (Other HH Income) & 6.311 & 2.364 & 6.967 & 0.842 & 6.415 & 3.192 \\
\hline Having Child & 0.086 & 0.281 & 0.117 & 0.321 & 0.126 & 0.331 \\
\hline No of Pens. Age & 0.255 & 0.516 & 0.285 & 0.520 & 0.313 & 0.571 \\
\hline Pension & 0.270 & 0.444 & 0.306 & 0.461 & 0.255 & 0.436 \\
\hline North East & 0.051 & 0.219 & 0.025 & 0.156 & 0.040 & 0.196 \\
\hline North West & 0.119 & 0.323 & 0.086 & 0.280 & 0.107 & 0.310 \\
\hline Yorkshire \& Humber & 0.089 & 0.286 & 0.069 & 0.254 & 0.079 & 0.270 \\
\hline East Midlands & 0.083 & 0.276 & 0.069 & 0.254 & 0.087 & 0.283 \\
\hline West Midlands & 0.100 & 0.300 & 0.058 & 0.234 & 0.082 & 0.274 \\
\hline East of England & 0.093 & 0.290 & 0.074 & 0.262 & 0.094 & 0.292 \\
\hline London & 0.094 & 0.292 & 0.044 & 0.205 & 0.101 & 0.301 \\
\hline South East & 0.131 & 0.338 & 0.097 & 0.295 & 0.127 & 0.333 \\
\hline South West & 0.095 & 0.293 & 0.073 & 0.261 & 0.098 & 0.297 \\
\hline Wales & 0.059 & 0.236 & 0.209 & 0.407 & 0.080 & 0.272 \\
\hline
\end{tabular}




\begin{tabular}{lcccccc} 
Scotland & 0.086 & 0.281 & 0.196 & 0.397 & 0.105 & 0.307 \\
\hline Number of Obs. & \multicolumn{2}{c}{928} & \multicolumn{2}{c}{1206} & & 4667 \\
\hline \hline
\end{tabular}

Tables 1 and 2 present the summary statistics of the sample separately for men and women. The values for categorical variables represent the proportion of older people with those characteristics in both tables. Of the respondents, those aged between 50 and 65 are chosen in both the BHPS and UKHLS. The age variable is divided into three main groups: 50-54 (base category), 55-59 and 60-65. The average age of the respondents is around 57 years for both men and women. Of all the respondents, 1,036, 1,455 and 5,733 are female for the 1991-1992, 2008-2009 and 2012-2013 waves, respectively. On the other hand, the total number of men in each wave is 928, 1,206 and 4,667, respectively. From 1991 to 2013, the retirement rate has consistently decreased by 11 per cent for women.

A five-point scaled self-assessed health variable is included in the both BHPS and UKHLS. However, a continuity problem arises with this variable as the question that the respondents were asked about their health changed in the ninth wave of the BHPS and after that in the UKHLS. I follow the method of Hernandez-Quevedo et al. (2005) to achieve consistency in all waves and recode the self-rated health variable into a four-category scale; poor health (poor or very poor health), fair health, good health (good or very good health) and excellent health ${ }^{5}$. Poor health is considered as a base category.

Highest academic qualification is taken as the education variable and categorised into four main groups based on studies by Rice et al. (2007) and Jones and Wildman (2008). The higher degree includes all university degrees. The second group covers all college degrees including higher national diploma (HND) and higher national certificate (HNC) and further education including A-level diploma. The third category includes all primary and secondary education levels. The last group is no qualification taken as a base category. Older women are more likely to achieve higher educational qualifications than men, particularly after 2008. The number of older women with at least a university degree increases considerably from 3.1 per cent to 14 per cent between 1991-1992 and 2008-2009 periods. On the other hand, having no formal qualifications is also more common among women. A dummy is used to represent the spousal relationship, which covers both marriage and partnership. Measuring logarithm of hourly earnings ${ }^{6}$ are derived from the last payment received dividing by the period of the last payment, and it is taken regarding real values based on 2005 Consumer Price Index ${ }^{7}$.

Housing tenure, non-labour income, income of other household members and pension eligibility are used to control for wealth effects on the retirement decision. Housing wealth is categorised into three groups: people who own their house/flat outright, own with a mortgage or rent. The rent category includes people who live in either privately rented or local authority rented housing. The mortgage is taken as a base category. The non-labour income for the last month in real terms is taken in logarithm form. Income of other household members is calculated by subtracting the respondent's labour and non-labour income from the total household income, and its logarithm is used in the models. Many studies used pension eligibility to examine the effect of pension system on the retirement decision. This is a strong proxy leading to earlier retirement. This variable is taken as a dichotomous variable, with a value of 1 for those who are eligible for pension income. There are some differences in the financial situations of older men and women throughout the two decades studied. The mean logarithm earnings reveal that men earn more than women. On the other hand, the increase in the hourly earnings of women is higher than that of men. The main reason could be the marked improvement in the educational qualifications and thus the steady increase in the labour force participation of mature-aged women over the past two decades. The non-labour income of men is higher than the non-labour income of women in early 1990s, whereas this trend reversed by 2008-2009 period. Another important aspect of the financial situation is housing tenure. Women are more likely to own their home outright, whereas men are more likely to have their own home but be paying off mortgages.

Two other covariates that are used in the study are dummies for having a caring responsibility and having a dependent child under 16. Women are more likely to have caring responsibilities than men, as expected. However, opposite to the expectations, men are more likely to have children under the age of 16 that they are responsible for. The proportion of men with children under 16 years old is almost twice that of women for all waves in this study. Finally, to represent regional differences, eleven regions based on the Government Office Region in both the BHPS and UKHLS are used as regional dummies. These regions are North East, North West, Yorkshire and Humber, East Midlands, West Midlands, East of England, London, South East, South West, Wales, and Scotland. Northern Ireland is removed from the sample to establish a comparison between the waves since the first wave of the BHPS begins with the British sample, which consists of England, Wales and Scotland. As for the region of residence, a higher proportion of both males and females live in the South East compared to

\footnotetext{
${ }^{5}$ Rice et al. (2007) and Garcia-Gomez et al. (2010) also used the same categorisation in their research.

${ }^{6}$ Selection bias is considered in estimating hour earnings by using Heckman 2-step procedure. See Heckman, 1974 for more details about Heckman procedure.
}

${ }^{7}$ All income and wealth variables in the study are taken in real terms based on 2005 Consumer Price Index. 
those living in other areas. North East region is considered as a base category in this study. To deal with the overrepresentation problem, cross-sectional weights are used for the boost samples for Scotland, and Wales added in the 2008/2009 wave.

\section{FINDINGS AND DISCUSSIONS}

\subsection{Estimation Results by Yun Models}

The decomposition analysis allows us to examine the gender differences in retirement attitudes by distinguishing the differences sourced from observable characteristics and coefficient effects and how the gender gap changes over 20 years. Two non-linear models proposed by Yun (2004) and Fairlie (2005) are used to compare the consistency of results derived from two different models.

Table 3 reports the results of the more detailed decomposition analysis proposed by Yun (2004) to show the gender differences in retirement decisions ${ }^{8}$. The main advantage of this method is that it provides detailed decomposition for both characteristics and return to risk components and gives evidence of the contribution of each factor to explain the gender gap in the retirement decision.

Table 3: Yun Decomposition Results

\begin{tabular}{|c|c|c|c|c|c|c|}
\hline & \multicolumn{2}{|c|}{ 1991-1992 } & \multicolumn{2}{|c|}{ 2008-2009 } & \multicolumn{2}{|c|}{ 2012-2013 } \\
\hline & Coef. & $\%$ & Coef. & $\%$ & Coef. & $\%$ \\
\hline \multirow[t]{2}{*}{$E$} & $0.043 * *$ & 16.92 & $0.073 * * *$ & 35.57 & $0.020 * * *$ & 16.22 \\
\hline & (2.111) & & (6.482) & & (3.351) & \\
\hline \multirow[t]{2}{*}{ C } & $0.209 * * *$ & 83.08 & $0.131 * * *$ & 64.43 & $0.101^{* * *}$ & 83.78 \\
\hline & (8.177) & & (7.685) & & (11.080) & \\
\hline $\mathbf{N}$ & 1956 & & 2586 & & 10437 & \\
\hline
\end{tabular}

\begin{tabular}{|c|c|c|c|c|c|c|}
\hline & 199 & & 200 & & 201 & \\
\hline & (E) & (C) & (E) & (C) & (E) & (C) \\
\hline & $\%$ & $\%$ & $\%$ & $\%$ & $\%$ & $\%$ \\
\hline Total Age Effect & -1.315 & -8.889 & 2.265 & -14.954 & -2.944 & 7.376 \\
\hline $55-59$ & $1.056 * * *$ & 0.345 & $-0.080^{*}$ & -6.786 & $0.724 * * *$ & 8.208 \\
\hline & $(2.593)$ & $(0.0746)$ & $(-1.684)$ & $(-0.915)$ & (5.318) & $(1.645)$ \\
\hline $60-65$ & $-2.371 * * *$ & -9.234 & $2.345^{*}$ & -8.168 & $-3.668 * * *$ & -0.831 \\
\hline & $(-2.843)$ & $(-1.458)$ & (1.661) & $(-0.792)$ & $(-6.274)$ & $(-0.113)$ \\
\hline Total Health Effect & 15.117 & 15.187 & 10.079 & 37.244 & 13.776 & 20.399 \\
\hline Fair & $-16.573 * * *$ & 1.287 & $1.361^{* * *}$ & 6.626 & $-6.836 * * *$ & -0.284 \\
\hline & $(-3.478)$ & $(0.366)$ & (4.584) & $(0.972)$ & $(-8.761)$ & $(-0.0757)$ \\
\hline Good & $-27.934 * * *$ & 9.378 & $-7.007^{* * *}$ & $24.427^{*}$ & $31.275^{* * *}$ & $14.653 * *$ \\
\hline & $(-5.225)$ & $(1.222)$ & $(-6.734)$ & $(1.837)$ & (9.959) & (2.293) \\
\hline Excellent & $59.624 * * *$ & 4.522 & $15.724 * * *$ & 6.191 & $-10.663^{* * *}$ & 6.030 \\
\hline
\end{tabular}

\footnotetext{
${ }^{8}$ The results are estimated in terms of the percentage of the gender gap attributable to differences in both endowment and coef ficients.
} 


\begin{tabular}{|c|c|c|c|c|c|c|}
\hline & (5.429) & (0.799) & (6.947) & $(0.942)$ & $(-11.08)$ & (0.987) \\
\hline \multirow[t]{2}{*}{ Spouse/Partner } & $-51.174 * * *$ & $35.024^{* *}$ & $-16.00 * * *$ & 47.557 & $-39.694 * * *$ & 13.960 \\
\hline & $(-3.089)$ & (2.007) & $(-3.961)$ & $(1.553)$ & $(-4.674)$ & $(0.806)$ \\
\hline Total Tenure Effect & 15.237 & -2.043 & 14.290 & -5.634 & 34.592 & -4.588 \\
\hline \multirow[t]{2}{*}{ Own House } & $13.591^{* *}$ & 2.483 & $9.352 * * *$ & 1.275 & $29.387^{* * *}$ & 0.372 \\
\hline & $(2.251)$ & (0.531) & (4.997) & (0.134) & $(8.807)$ & $(0.064)$ \\
\hline \multirow[t]{2}{*}{ Rent } & 1.645 & -4.526 & $4.938 * * *$ & -6.908 & $5.204 * * *$ & -4.960 \\
\hline & $(0.432)$ & $(-1.230)$ & $(4.540)$ & $(-1.619)$ & $(5.906)$ & $(-1.335)$ \\
\hline Total Educ. Effect & 30.418 & 7.139 & 2.952 & -13.092 & 39.184 & -51.119 \\
\hline \multirow[t]{2}{*}{ Higher Degree+ } & $17.676^{* * *}$ & -0.565 & $1.752^{* *}$ & -0.680 & $36.122 * * *$ & $-22.475^{* * *}$ \\
\hline & $(2.854)$ & $(-0.356)$ & (1.970) & $(-0.127)$ & $(6.490)$ & $(-4.242)$ \\
\hline \multirow[t]{2}{*}{ HND/HNC, A Level } & $12.418^{*}$ & 2.153 & $8.441^{*}$ & -3.634 & $20.765^{* * *}$ & $-20.297^{* * *}$ \\
\hline & $(1.666)$ & $(0.800)$ & (1.749) & $(-0.483)$ & (7.430) & $(-3.838)$ \\
\hline \multirow[t]{2}{*}{ CSE/O Level } & 0.324 & $5.550 * *$ & $-7.241 * * *$ & $-8.779 *$ & $-17.704 * * *$ & $-8.346 * * *$ \\
\hline & $(0.623)$ & (2.077) & $(-2.984)$ & $(-1.698)$ & $(-5.593)$ & $(-2.637)$ \\
\hline \multirow[t]{2}{*}{ Care } & 2.291 & 0.804 & $1.558^{* *}$ & 3.634 & $6.683^{* * *}$ & 0.220 \\
\hline & $(1.099)$ & $(0.717)$ & $(2.289)$ & $(1.543)$ & $(4.412)$ & $(0.152)$ \\
\hline \multirow[t]{2}{*}{ In (Hourly Earnings) } & $107.981 * * *$ & $-127.751 *$ & $28.276^{*}$ & $-141.985^{*}$ & -14.949 & -56.732 \\
\hline & $(2.647)$ & $(-2.726)$ & $(1.953)$ & $(-1.679)$ & $(-0.536)$ & $(-1.243)$ \\
\hline \multirow[t]{2}{*}{ In (Non-Lab. Inc.) } & $-20.892 * * *$ & $-131.579 *$ & $45.793 * * *$ & $-30.916^{*}$ & $38.061^{* * *}$ & $-50.891 * * *$ \\
\hline & $(-5.299)$ & $(-8.642)$ & (12.66) & $(-1.725)$ & $(15.32)$ & $(-5.515)$ \\
\hline \multirow[t]{2}{*}{ In (Other HH Inc.) } & $17.958^{* *}$ & -17.464 & $2.772 * * *$ & 0.547 & $1.382^{* *}$ & $54.950 * * *$ \\
\hline & (2.093) & $(-0.860)$ & (2.713) & $(0.0166)$ & $(2.178)$ & $(2.833)$ \\
\hline \multirow[t]{2}{*}{ Children } & $-18.404^{*}$ & 2.124 & 0.259 & -1.374 & -0.139 & $6.970 * *$ \\
\hline & $(-1.898)$ & $(1.027)$ & (0.089) & $(-0.338)$ & $(-0.018)$ & $(2.439)$ \\
\hline \multirow[t]{2}{*}{ No of Pens. Age } & 26.526 & 0.842 & 15.310 & $-13.129 * *$ & $46.173^{* *}$ & -6.297 \\
\hline & $(0.996)$ & $(0.285)$ & $(1.540)$ & $(-2.419)$ & $(2.322)$ & $(-1.559)$ \\
\hline \multirow[t]{2}{*}{ Pension } & $-19.671^{* * *}$ & -0.253 & $-6.345^{* * *}$ & -4.145 & $-23.061 * * *$ & 4.624 \\
\hline & $(-2.832)$ & $(-0.0699)$ & $(-3.084)$ & $(-0.651)$ & $(-7.001)$ & $(1.220)$ \\
\hline Total Region Effect & -3.751 & 13.833 & -1.357 & -3.840 & 1.036 & 10.749 \\
\hline \multirow[t]{2}{*}{ North West } & -2.347 & -2.172 & 0.181 & -7.015 & 0.219 & -2.099 \\
\hline & $(-1.454)$ & $(-0.701)$ & $(0.798)$ & $(-1.459)$ & $(0.487)$ & $(-0.598)$ \\
\hline \multirow[t]{2}{*}{ Yorkshire \& Humber } & 0.742 & $4.746^{*}$ & 0.104 & 1.153 & -0.040 & 2.574 \\
\hline & $(0.665)$ & $(1.928)$ & $(0.395)$ & (0.293) & $(-0.110)$ & $(0.966)$ \\
\hline East Midlands & 1.239 & 1.971 & -0.690 & 0.142 & 0.354 & 0.774 \\
\hline
\end{tabular}




\begin{tabular}{lcccccc} 
& $(0.703)$ & $(0.879)$ & $(-0.421)$ & $(0.035)$ & $(0.227)$ & $(0.264)$ \\
West Midlands & 2.488 & -0.522 & 0.013 & 0.771 & -0.029 & 0.507 \\
& $(1.445)$ & $(-0.195)$ & $(0.053)$ & $(0.218)$ & $(-0.242)$ & $(0.182)$ \\
East of England & -0.690 & $5.167^{* *}$ & 0.179 & -3.710 & 0.268 & 2.832 \\
& $(-0.354)$ & $(1.983)$ & $(0.319)$ & $(-0.866)$ & $(0.458)$ & $(0.895)$ \\
London & $-2.559 *$ & 3.962 & -0.400 & 0.591 & 0.067 & 2.228 \\
& $(-1.731)$ & $(1.513)$ & $(-0.618)$ & $(0.219)$ & $(0.073)$ & $(0.671)$ \\
South East & $-3.427 *$ & 1.962 & -0.183 & -3.267 & -0.363 & 0.331 \\
& $(-1.663)$ & $(0.586)$ & $(-0.949)$ & $(-0.612)$ & $(-0.647)$ & $(0.081)$ \\
South West & 2.237 & 0.560 & 0.056 & 2.031 & 0.546 & 1.257 \\
& $(1.580)$ & $(0.213)$ & $(0.589)$ & $(0.475)$ & $(1.569)$ & $(0.388)$ \\
Wales & -0.488 & -0.856 & -0.298 & 3.725 & 0.028 & 1.673 \\
& $(-0.674)$ & $(-0.492)$ & $(-0.344)$ & $(0.339)$ & $(0.130)$ & $(0.610)$ \\
Scotland & -0.946 & -0.986 & -0.319 & 1.740 & -0.014 & 0.671 \\
Constant & $(-0.572)$ & $(-0.437)$ & $(-0.186)$ & $(0.170)$ & $(-0.321)$ & $(0.194)$ \\
& & $312.919 * * *$ & & $240.458 * * *$ & & $150.495 * * *$ \\
\hline \hline
\end{tabular}

Notes: The omitted variables are age group 50-54, no qualification, poor health, having own home with paying mortgage and North East; $\mathrm{t}$ statistics in parentheses; * significant at 10\%-level; ** significant at 5\%-level; *** significant at 1\%-level; High outcome group: Female.

The results show that the gender differences in retirement are explained mostly by the differences in unobservable characteristics. There are no marked differences in either the explained or the unexplained parts of the gender disparity over 20 years. Taking account of the characteristics, 17 per cent of the actual gap is explained by differences in endowment effects, whereas almost 83 per cent of the gap is attributable to differences in unobservable factors in the early 1990s. Even though there is an improvement in the gender gap during the period, this has been reversed after the crisis period.

The specific decomposition method suggests that the gap in the outcome could be reduced by closing the gap in characteristics with positive contributions while widening the gap in characteristics with negative contributions ${ }^{9}$. Some changes that may be conducive to the higher retirement rate among females are dependent on the level of their education, deterioration in health status, their income and other household effects. When specific factor contributions are considered, the results from Yun's decomposition model show that the role of age changed over time. It imposes no fixed pattern on gender differentials.

Health affects the gender gap in the retirement patterns through the differences in characteristics as their coefficients are statistically significant. The positive effect of the excellent health dominates the negative effects of worse health groups compared to poor one due to the differences in observable factors except for the 2012-2013 period. The marital effect on the gender disparity in retirement probabilities produces different patterns. The salient point is that the effect of marital status enlarges the gender gap over the differences in observable factors, whereas it reduces the gender disparity based on differences in coefficients. Marital status is found to be one of the most significant contributing factors increasing the gender gap owing to the changes in endowment especially for the initial period, while this effect lowers the gender disparity based on the differences in coefficients that is mostly found as insignificant. As another household factor, the impact of caring responsibilities on the gender gap in the retirement is somewhat smaller than the other factors in the decomposition model except for its positive effects in reducing the gender disparity owing to the differences in the endowment part for both the

\footnotetext{
${ }^{9}$ A positive coefficient in the endowment part indicates the expected reduction in gender differentials of being retired if females were equal to males. On the other hand, a negative coefficient associated with the differences in coefficients shows the expected increase in the gender gap if females had the same behavioural responses as males. See Yun (2004) and Kalb et al. (2012) for detailed explanations.
} 
crisis and post-crisis periods. However, the other coefficients estimated for the contribution of caring responsibility in explaining gender gap are found to be insignificant.

Almost a third of the explained gap in the probability of retirement between women and men is attributed to educational attainments in the first wave. On the other hand, this effect based on the differences in the unexplained part notably reduces over time and turns out to be negative, increasing the gender gap during the crisis period. However, education has more impact on the gender gap owing to the changes in coefficients. Looking at the results in more details, attainment of at least a university degree contributes most to the decrease in the female-male disparity in retirement decisions. This effect is based on differences in observable characteristics. However, a lower level of education expands the gap more in favour of males by the crisis period.

The income variables make considerable contributions to explaining the gender gap in the retirement behaviours. Hourly earnings have a significant positive impact on the gender gap favouring women. However, this positive contribution declined during the 20-year period. It negatively affects the gender gap against females after the crisis owing to the differences in observable factors although the corresponding coefficient is found to be insignificant in 2012-2013. Another notable finding is that a highly remarkable adverse coefficient effect surpasses the positive composition effect leading to a considerable expansion in favour of men in the gender gap. Non-labour income also has a substantial impact on explaining the gender disparity in the retirement decisions of older people. Non-labour income widens the gender gap by nearly 21 per cent owing to the differences in observable characteristics. Further, it extends the gap by more than 100 per cent due to the differences in the coefficients at the beginning of the 1990s. Thus, non-labour income is found to be the most contributing factor affecting the gender gap for the period of 1991-1992. On the other hand, the positive contribution based on the gender gap owing to the differences in endowment effect is dominated by the negative contribution based on differences in coefficients in the last period. As for the income of other household members, the gender gap is reduced based on the differences in observable factors. However, this positive attribution reduces significantly over time. The other wealth effect, pension eligibility, also has a negative contribution, expanding the gap by 20 per cent in the first period and 23 per cent at the latest period. The coefficients based on differences in coefficients were found to be insignificant.

Housing tenure has a different impact on the gender gap in retirement decisions. The coefficient effects for the set of dummies, owning house and rent, were found to be insignificant. On the other hand, the endowment effects of both sets of dummies are found to be responsible for a more significant portion of the reduction in the gender gap for the exit decision of the elderly. It should be noted that owning a house is the main factor to contribute positively to the gender gap.

The household characteristics such as having children under the age of 16 and number of people at a pensionable age in the household induce different patterns on the gender differences in retirement decisions. The effect of having children under 16 increases the gender gap by almost 18 per cent in the first period when the significance of the endowment effect is taken into account. On the other hand, the positive impact stemming from the differences in coefficients increased the gap by 7 per cent in the most recent period. The number of pensionable-age people in the household is positively associated with narrowing the gender gap in the retirement of the elderly in the post-crisis period. Its effect is attributed to the decrease in gender differences by 13 per cent based on the changes in observable characteristics. However, its effect negatively contributes to the gender differences against women due to differences in the unobservable group in the crisis period. The other coefficients were found to be insignificant. Lastly, the endowment effects of regional dummies do not explain much of variation of the gender gap. Most coefficients are insignificant.

\subsection{Estimation Results by Fairlie Models}

The decomposition coefficients estimated in Table 4 are drawn from the pooled sample. Taking a pooled sample is advantageous since it incorporates the full market response and does not exclude rapidly growing sub-groups of the population (Fairlie and Robb, 2007). To average across possible ordering combinations and estimate the coefficients of decomposition, we use average decomposition results across 1000 randomly drawn replications while randomising the order of the variables. The percentages in the results are the contributions of the factors to explain gender differences in retirement based on differences in the endowment. By using female coefficients, a very small per cent of the gap is explained by the gender differences in all of the included variables in the first period, 1991-1992. The small contribution is mainly due to the higher negative contributions of some variables, such as non-labour income. In the 2008-2009 period, the gender variation in retirement behaviour has a remarkable increase, and 28 per cent of the gap is explained by the gender differences, whereas 17 per cent of the gap is explained by the gender differences in the latest period. The coefficient of the gender gap, which is given as male/female gap is negative. This result implies that women have disadvantages in the retirement process as they retire earlier than men. Table 4 also presents an estimation of attributions of gender differences in a specific subset of variables to the retirement decisions. The positive per cent (negative coefficient) indicate that gender differences in the 
covariates decrease the gender gap in the retirement patterns. On the other hand, the negative per cent (positive coefficient) means a negative attribution to the gap.

Table 4: Fairlie Decomposition Results

\begin{tabular}{|c|c|c|c|}
\hline & (1) & (2) & (3) \\
\hline & 1991-1992 & 2008-2009 & 2012-2013 \\
\hline Male mean & 0.262 & 0.244 & 0.270 \\
\hline Female mean & 0.514 & 0.439 & 0.381 \\
\hline M-F Differences & -0.252 & -0.194 & -0.112 \\
\hline \multicolumn{4}{|c|}{ Contributions from Gender Differences } \\
\hline \multirow[t]{2}{*}{ Age } & -0.00134 & $-0.00513^{* *}$ & $-0.00186 * * *$ \\
\hline & $(-1.136)$ & $(-2.204)$ & $(-3.268)$ \\
\hline$\%$ & 0.53 & 2.64 & 1.66 \\
\hline \multirow[t]{2}{*}{ Health } & -0.00186 & $-0.00535 * * *$ & -0.000543 \\
\hline & $(-1.127)$ & $(-3.733)$ & $(-1.119)$ \\
\hline$\%$ & 0.74 & 2.75 & 0.49 \\
\hline \multirow[t]{2}{*}{ Spouse/Partner } & $0.0169 * * *$ & $0.0117^{* * *}$ & $0.00457^{* * *}$ \\
\hline & (3.639) & (3.785) & $(4.323)$ \\
\hline$\%$ & -6.71 & -6.02 & -4.09 \\
\hline \multirow[t]{2}{*}{ Housing Tenure } & $-0.00453^{* *}$ & $-0.00789 * * *$ & $-0.00308 * * *$ \\
\hline & $(-2.369)$ & $(-4.504)$ & $(-5.953)$ \\
\hline$\%$ & 1.80 & 4.06 & 2.76 \\
\hline \multirow[t]{2}{*}{ Education } & $-0.00622 * * *$ & -0.00106 & $-0.00456 * * *$ \\
\hline & $(-2.790)$ & $(-0.287)$ & $(-4.886)$ \\
\hline$\%$ & 2.47 & 0.55 & 4.08 \\
\hline \multirow[t]{2}{*}{ Care } & -0.000341 & -0.00104 & $-0.000549 * * *$ \\
\hline & $(-1.067)$ & $(-0.975)$ & $(-3.179)$ \\
\hline$\%$ & 0.14 & 0.53 & 0.49 \\
\hline \multirow[t]{2}{*}{ In (Hourly E) } & $-0.0210 * *$ & $-0.0139 * *$ & 0.00185 \\
\hline & $(-2.098)$ & $(-1.976)$ & $(0.677)$ \\
\hline$\%$ & 8.34 & 7.15 & -1.66 \\
\hline \multirow[t]{2}{*}{ In (Non-Lab Inc.) } & $0.0123^{* * *}$ & $-0.0119 * * *$ & $-0.00287 * * *$ \\
\hline & (6.499) & $(-5.503)$ & $(-4.088)$ \\
\hline$\%$ & -4.88 & 6.12 & 2.57 \\
\hline \multirow[t]{2}{*}{ In (Other HH Inc.) } & $-0.00569 *$ & $-0.00714^{* * *}$ & $-0.00230 * * *$ \\
\hline & $(-1.652)$ & $(-3.078)$ & $(-4.076)$ \\
\hline
\end{tabular}




\begin{tabular}{lccc} 
\% & 2.26 & 3.67 & 2.06 \\
Children & 0.00120 & 0.00122 & $-0.00137^{*}$ \\
$\%$ & $(1.100)$ & $(0.829)$ & $(-1.960)$ \\
No of Pens Age & -0.48 & -0.63 & 1.23 \\
& 0.00131 & $-0.0226^{* * *}$ & $-0.0121^{* * *}$ \\
$\%$ & $(0.194)$ & $(-2.863)$ & $(-4.330)$ \\
Pension & -0.52 & 11.62 & 10.83 \\
& $0.0110 * * *$ & $0.00757^{* * *}$ & $0.00364^{* * *}$ \\
$\%$ & $(5.266)$ & $(3.401)$ & $(7.395)$ \\
Region & -4.37 & -3.89 & -3.26 \\
& 0.000168 & 0.000424 & $9.56 \mathrm{e}-06$ \\
$\%$ & $(0.434)$ & $(0.923)$ & $(0.106)$ \\
\hline All income variables & -0.07 & -0.22 & -0.01 \\
\hline $\mathrm{N}$ & 0.002 & -0.055 & -0.019 \\
\hline
\end{tabular}

Notes: (1) All specifications use coefficient estimates from the full sample of both genders. (2) Contribution estimates are mean values of the decomposition using 1000 subsamples of females. (3) T-statistics are reported in parentheses below contribution estimates.

The estimates indicating contributions to the gender disparity differ substantially in some covariates through periods. While age differences between females and males explain only a small part of the gap in the first BHPS wave, the effect of age on the gender gap slightly increases in both crisis and post-crisis periods. Another result found using Fairlie decomposition model is that gender differences in health have no significant effect and almost no contribution to the gap in the outcome for the older people in the first and last periods. One reason may be that the negative effect of one of the health levels is dominated by the positive effects of the other levels, so the net effect is almost none. The spousal effect is one of the most important effects on the gender gap in the Fairlie, decomposition model and it has a negative contribution to the gender gap in all waves.

The differences in housing tenure have a positive impact on the gender disparity in retirement, but the difference between males and females in tenure explains a small part of the gap. However, its explanatory power on the gender gap slightly increases over time, making all coefficients statistically significant. The gender differences in educational attainment also provide a substantial and positive contribution to the gap, except for the crisis period. The income variables remarkably contribute to the gender differences in retirement behaviour as well. The effect of hourly earnings is the strongest of the financial variables for older men and women for the initial period. Conversely, the differences in non-labour income provide a negative contribution to the gap, and only 5 per cent of the variation is explained by non-labour income in the first wave. For the latest crisis period, the contributions of the income variables to the explanation of the gender gap are substantially less than those to explanation of the gap in previous periods. Additionally, the income of other household members was found to be a significant financial factor explaining the gap. Regarding the other household characteristics, differences in caring and children responsibilities, have opposite impacts on the gender gap but explain only a small part of the gender disparity in retirement. Both are only significant for the latest period. The reason could be a weak relationship between these responsibilities and the probability of retirement. However, the number of pensionable aged people in the household explains the largest part of the gap, approximately 11.5 and 10.2 percentage points, respectively, for the periods 2008-2009 and 2012-2013. Regional differences were found to be insignificant and explain virtually none of the gender variation in the retirement behaviour of older people in the UK in all periods.

Finally, according to the results obtained by decomposing the factors affecting the retirement behaviours of the elderly, there are significant differences between the results obtained using the decomposition methods of Yun and Fairlie. While 17 per cent of the gender gap is attributable to the differences in the explained part in the Yun decomposition method, the explained 
part of the first wave is much lower using Fairlie's method. However, the differences between these two methods in explaining the gender gap decline in the crisis period. After the crisis period, both models give similar results for the contribution of observable factors in the gender gap. Moreover, the results of the Fairlie decomposition method are based on the differences in characteristics (explained part) and provide evidence only about how much of the differences in the retirement behaviour between male and female groups can be explained by the differences in each variable used in the model. On the other hand, Yun decomposition analysis also provides detailed decomposition results to explain how the differences in the behavioural response are associated to each factor used in the model (coefficient effect) in addition to the results based on the characteristics effect (Yun, 2004). Therefore, the proportion of the covariates that explain the gender gap is different between the two methods. As for the differences in observable factors, both methods indicate the same direction regarding either a positive or a negative contribution of these factors to the gender disparity. However, the explanatory power of factors on the gender gap is much less in the Fairlie model than that found by the Yun method. Another major difference is that both models use different weight procedure for the contribution of each variable based on the differences in characteristics. While Yun (2004) uses a first-order Taylor expansion to linearize the characteristics and coefficient effects at their mean values in the decomposition model, the first term of decomposition component is weighted using coefficient estimates from a pooled sample of two groups suggested by Oaxaca and Ransom (1994) in the Fairlie decomposition method. Furthermore, each observation obtained by drawing a random subsample of females equal in size to the full male sample from the pooled sample is ranked according to the predicted probabilities and matched by their respective rankings (Fairlie, 2005). Hence, the coefficient estimations are sensitive to the order of the variables in the Fairlie model.

\section{CONCLUSION}

Over the past two decades, older women have made tremendous progress in labour-market participation, and this ongoing upward trend only slowed down during the recession period in the UK. Although more women have recently been staying in the workforce longer as a result of improvements in the working conditions and raising the female state pension age, findings suggest that there are still considerable gender differences in the labour market dependent on changes in both variables and coefficients. From the view of retirement decisions, the gender variation that is associated with both explained part and unexplained part of the gap have not significantly changed over time. However, the effects of both demographic and financial factors causing the gender gap have significantly changed over the 20-year period. The corresponding results derived from the Fairlie decomposition method are less than those found by using Yun decomposition techniques in explaining the gender disparity owing to differences in the endowment except the latest period. The post-crisis period is the only time interval for which both the Yun and Fairlie models converge in explaining the gender gap due to differences in characteristics. When the contribution of each factor to the gender gap is taken into account, the results obtained using the Yun model explain a larger part of the gender gap due to the differences in observable characteristics. One of the main reasons for these differences between the two techniques is the relevance of path dependence, which is attributed to the fact that Fairlie decomposition estimates could be sensitive to the ordering of variables because of the nonlinearity of the prediction equations (Fairlie, 2015). Secondly, the weights used for the contribution of each variable to the characteristics effect are different in both models. Hence, comparing these two models, the Yun model gives more precise results to determine the effects of both individual and household factors on the gender differences in the retirement process and how the contributions of these factors change through the given period.

\section{REFERENCES}

Bauer, T. and Sinning, M. (2008). An extension of the Blinder-Oaxaca decomposition to nonlinear models. AStA Advances in Statistical Analysis, 92(2), 197-206.

Bazen, S., Joutard, X. and Magdalou, B. (2016). An Oaxaca decomposition for nonlinear models. IZA Discussion Paper No. 9909, Bonn: Institute for the Study of Labour.

Blinder, A.S. (1973). Wage discrimination: reduced form and structural estimates. The Journal of Human Resources, 8(4), $436-455$.

Bowblis, J. R., and Yun, M.S. (2010). Racial and ethnic disparities in the use of drug therapy. Social Science Research, 39, 674-684.

Chiu, Chuang-Yi and Chen, J. (2013). Determinants of labour force participation of older married men in Taiwan. Economics Bulletin, 33(4), 3088-3101.

DWP (2015). Employment statistics for workers aged 50 and over, by 5-year age bands and gender: from 1984 to 2015 . London: Department of Work and Pensions. Retrieved from

https://www.gov.uk/government/uploads/system/uploads/attachment_data/file/473821/employment-stats-workers-aged-50-and-over1984-2015.pdf. 
Fairlie, R. W. (1999). The absence of the African-American owned business: An analysis of the dynamics of self-employment. Journal of Labour Economics, 17(1), 80-108.

Fairlie, R.W. (2005). An extension of the Blinder-Oaxaca decomposition technique to logit and probit models. Journal of Economic and Social Measurement, 30(4), 305-316.

Fairlie, R.W. and Robb, A.M. (2007). Why are black-owned businesses less successful than white-owned businesses: the role of families, inheritances, and business human capital. Journal of Labour Economics, 25(2), 289-323.

Fairlie, R. W. (2015). Addressing path dependence and incorporating sample weights in the nonlinear Blinder-Oaxaca decomposition technique for logit, probit and other nonlinear models. Retrieved from: www. people.ucsc.edu/ rfairlie/papers/decomprevisted_v5.docx.

Fortin, N., Lemieux, T. and Firpo, S. (2011). Decomposition methods in Economics. in Ashenfelter, O. and Card, D. (eds.), Handbook of Labour Economics, vol. 4A. Amsterdam: Elsevier, 1-102.

Gangl, M. and Ziefle, A. (2009). Motherhood, labour force behaviour, and women's careers: An empirical assessment of the wage penalty for motherhood in Britain, Germany, and the United States. Demography, 46(2), 341-369.

Garcia-Gomez P., Jones, A. M. and Rice, N. (2010). Health effects on labour market exits and entries. Labour Economics, 17(1), 62-76.

Gunalp B., Cilasun S. M. and Acar E. O. (2015). Male-female labour market participation and the extent of gender-based wage discrimination in Turkey. Economics Discussion Papers No. 2015-56, Kiel: Kiel Institute for the World Economy.

Hernandez-Quevedo C., Jones A. M. and Rice N. (2005). Reporting bias and heterogeneity in self-assessed health: evidence from the British household panel survey. Health, Econometrics and Data Group (HEDG) Working Paper No. 05/04, York: University of York.

Jann, B. (2008). The Blinder-Oaxaca decomposition for linear regression models. The Stata Journal, 8(4), $453-479$.

Jones, A.M. and Wildman, J. (2008). Health, income, and relative deprivation: evidence from the BHPS. Journal of Health Economics, 27(2), 308-324.

Kalb, G., Le T. and Leung F. (2012). Decomposing differences in labour force status between indigenous and non-indigenous Australians. IZA Discussion Paper No. 6808, Bonn: The Institute for the Study of Labour.

Kunze, A. (2017). The gender wage gap in developed countries. IZA Discussion Paper No. 10826, Bonn: Institute for the Study of Labour.

Lynn, P. (ed.) (2006). Quality profile: British Household Panel Survey version 2.0: Waves 1 to 13: 1991-2003. Colchester: Institute for Social and Economic Research, University of Essex. Retrieved from: http://www.iser.essex.ac.uk/files/bhps/qualityprofiles/BHPS-QP-01-03-06v2.pdf.

Lynn, P. (2009). Sample design for Understanding Society. Understanding Society Working Paper No. 2009-01, Essex: Institute for Social and Economics Research.

Nielsen, H. S. (1998). Discrimination and detailed decomposition in a logit model. Economics Letters, 61, 115-120.

Oaxaca, R.L. (1973). Male-female wage differentials in urban labour markets. International Economic Review, 14(3), 693-709.

Oaxaca, R.L. and Ransom, M. (1994). On discrimination and the decomposition of wage differentials. Journal of Econometrics, 61(1), 5-21.

Powers, Da. and Pullum, G. (2006). Multivariate decomposition for nonlinear models, Paper presented at PPA conference, NJ: Princeton University.

Powers, D.A., Yoshioka, H. and Yun, M.S. (2011). Mvdcmp: multivariate decomposition for nonlinear response models. Stata Journal, 11(4), 556-576.

Pritchett, J. B., and Yun, M. S. (2009). The in-hospital mortality rates of slaves and freemen: Evidence from Touro Infirmary, New Orleans, Louisiana, 1855-1860. Explorations in Economic History, 46, 241-252.

Rice, N., Roberts, J. and Jones, A.M. (2007). Sick of work or too sick to work? evidence on health shocks and early retirement from the BHPS. SERP Working Papers No. 2007/002, Sheffield: University of Sheffield.

Yun, M. S. (2000). Decomposition analysis for a binary choice model. IZA Discussion Paper Series No. 145, Bonn: The Institute for the Study of Labour.

Yun, M.S. (2004). Decomposing differences in the first moment. Economic Letters, 82(2), 275-280.

Yun, M.S. (2005). Decomposing tests when decomposing differences in the first moment. Journal of Economic and Social Measurement, 30(4), 295-304.

Wagstaff, A. and Nguyen, N. N. (2002). Poverty and survival prospects of Vietnamese children under Doi Moi. World Bank Policy Research Working Paper No 2832, Washington DC: World Bank. 